\title{
Application of the Nuclear Microprobe to X-ray Microanalysis of Biological Materials in Frozen-hydrated State
}

\author{
G. Tylko ${ }^{1,2}$, J. Mesjasz-Przybyłowicz ${ }^{2}$ and W.J. Przybyłowicz ${ }^{2,3}$ \\ ${ }^{1}$ Department of Cytology and Histology, Institute of Zoology, Jagiellonian University, Ingardena 6, \\ 30-060 Kraków, Poland \\ ${ }^{2}$ Materials Research Group, iThemba LABS, P.O. Box 722, Somerset West 7129, South Africa \\ ${ }^{3}$ Faculty of Physics \& Applied Informatics, AGH University of Science and Technology, \\ Mickiewicza 30, 30-059 Kraków, Poland
}

A method of elemental analysis of biological samples in frozen-hydrated state using proton microbeam has been developed at iThemba LABS, South Africa. It permits localization and quantitative measurements of diffusible and bound elements within hydrated tissue and cell matrix at temperatures below $-160^{\circ} \mathrm{C}$, in vacuum. Technically, this development consisted of coupling a cryopreparation unit used in electron microscopy (Model E4700 manufactured by Bio-Rad Microscience Division, USA) with the experimental chamber of a nuclear microprobe (manufactured by Oxford Microbeams), after necessary modifications. This is the first such facility in the world [1]. Two earlier adaptations of nuclear microprobes for low temperature measurements enabled in-air analysis [2-3], with inferior beam diameter and spatial resolution in comparison to systems operating in vacuum.

Typical quantitative analysis using a nuclear microprobe is essentially standardless. Elemental concentrations are obtained on the basis of PIXE (particle induced x-ray emission) results computed using fundamental parameters method. Concentrations of light elements $(\mathrm{C}, \mathrm{N}, \mathrm{O}$, indirectly $\mathrm{H})$ and specimen thickness are obtained from proton backscattering method, and next used for matrix correction of PIXE. This approach is well established in analysis of dry specimens. Its utility for frozen-hydrated specimens has been tested by measurements of standards prepared as $20 \%$ gelatine solution with known concentrations of $\mathrm{PbCl}_{2}$ and $\mathrm{KI}$. Analytical capabilities of in-vacuum microPIXE of frozen-hydrated specimens were next tested on two examples of plant and animal material leaves of Senecio anomalochrous Hilliard (Asteraceae) and larvae of Chrysolina pardalina Fabricius (Chrysomelidae).

Specimens were frozen in propane cooled by liquid nitrogen, fractured, carbon coated and transferred onto the cold $\left(-170^{\circ} \mathrm{C}\right)$ cryostage in the experimental chamber of the nuclear microprobe. The temperature of the specimen support inside the chamber was maintained at $-170^{\circ} \mathrm{C}$ using $\mathrm{N}_{2}$ flow of $1.5 \mathrm{l} / \mathrm{min}$. The temperature of the anticontaminator was $-195^{\circ} \mathrm{C}$. Vacuum inside the chamber reached $5.5 \times 10^{-5} \mathrm{mBarr}$ during analysis. Proton beam of 3.0 MeV energy and current below $120 \mathrm{pA}$ was used, focused to a $2 \mu \mathrm{m} \times 3 \mu \mathrm{m}$ spot and raster scanned over the sample area with $10 \mathrm{~ms}$ dwelltime. PIXE and proton backscattering (BS) were used simultaneously. Data were collected using XSYS data acquisition system in a list mode. GeoPIXE II software was used for further data processing. True, quantitative elemental maps were generated off-line using dynamic analysis method [4-5]. The concentrations of elements and their minimum detection limits for each analytical point were also calculated on the basis of PIXE spectra extracted from the selected areas. The matrix composition and areal density was obtained from the analysis of corresponding BS spectra using a RUMP simulation package [6] and experimental, non-Rutherford cross-sections for isotopically natural $\mathrm{C}$ and $\mathrm{O}$ at laboratory angle of $170^{\circ}[7]$. 
Elemental mapping of plant and animal material in frozen-hydrated state revealed life-like distribution of elements under investigation. Examples of maps of $\mathrm{Ca}$ distribution in leaves of $S$. anomalochrous and $\mathrm{P}$ in the abdomen of Ch. pardalina are presented in Fig. 1. The lateral resolution of proton beam was sufficient to recognize different tissues like mesophyll, vascular bundles, subepidermis and epidermis in leaf samples as well as endothelium of a gut, Malpighian tubules and hemolymph in the abdomen of Ch. pardalina. The elemental composition is shown in Table 1 together with the values of the minimum detection limits, expressed in $\mu \mathrm{g} \mathrm{g}^{-1}$ wet mass. The main advantage of analysis of specimens in frozen-hydrated state by micro-PIXE is its 100 to 1000 times higher sensitivity in comparison with electron microprobes [8].

References

[1] G. Tylko et al., in preparation.

[2] P. Horowitz et al., Science 10 (1976) 1162.

[3] T. Sakai et al., Nucl. Instr. Meth. B 231 (2005) 112.

[4] C.G. Ryan et al., Nucl. Instr. Meth. B 77 (1993) 203.

[5] C.G. Ryan, Int. J. Imaging Syst. Technol. 11 (2000) 219.

[6] L.R. Doolittle. Nucl. Instr. Meth. B 15 (1986) 227.

[7] R. Amirikas et al., Nucl. Instr. Meth. B 77 (1993) 110.

[8] J.L. Campbell et al., Particle-Induced X-ray Emission Spectrometry (PIXE), John Wiley \& Sons, New York, 1996.

TABLE 1. Concentration of elements in leaves of Senecio anomalochrous and abdomen of Chrysolina pardalina ( $\mathrm{g} \mathrm{g}^{-1}$ wet mass) expressed as a mean \pm standard error. Minimum detection limits (MDL) are shown in parentheses.

\begin{tabular}{rcccccccccc}
\hline & $\mathbf{P}$ & $\mathbf{S}$ & $\mathbf{C l}$ & $\mathbf{K}$ & $\mathbf{C a}$ & $\mathbf{M n}$ & $\mathbf{F e}$ & $\mathbf{N i}$ & $\mathbf{C u}$ & $\mathbf{Z n}$ \\
\hline Senecio & Not & $1028 \pm 69$ & $6219 \pm 782$ & $2679 \pm 273$ & $1009 \pm 119$ & $31 \pm 5$ & $19 \pm 3$ & $115 \pm 11$ & $5 \pm 0.3$ & $8 \pm 1$ \\
anomalochrous & analysed & $(12)$ & $(7.5)$ & $(4.5)$ & $(3.9)$ & $(1.3)$ & $(1.1)$ & $(1.4)$ & $(1.5)$ & $(1.5)$ \\
Chrysolina & $2249 \pm 222$ & $634 \pm 60$ & $2741 \pm 169$ & $4603 \pm 251$ & $318 \pm 46$ & $9 \pm 2$ & $37 \pm 8$ & $50 \pm 32$ & $19 \pm 5$ & $27 \pm 3$ \\
pardalina & $(21)$ & $(10.5)$ & $(6.2)$ & $(2.8)$ & $(2.5)$ & $(1.0)$ & $(0.9)$ & $(1.0)$ & $(1.0)$ & $(1.0)$ \\
\hline
\end{tabular}

FIG. 1. Quantitative elemental maps of $\mathrm{Ca}$ and $\mathrm{P}$ distribution in Senecio anomalochrous leaf (a) and Chrysolina pardalina abdomen (b), respectively analyzed in frozen-hydrated state. Bar: $1000 \mu \mathrm{m}$.
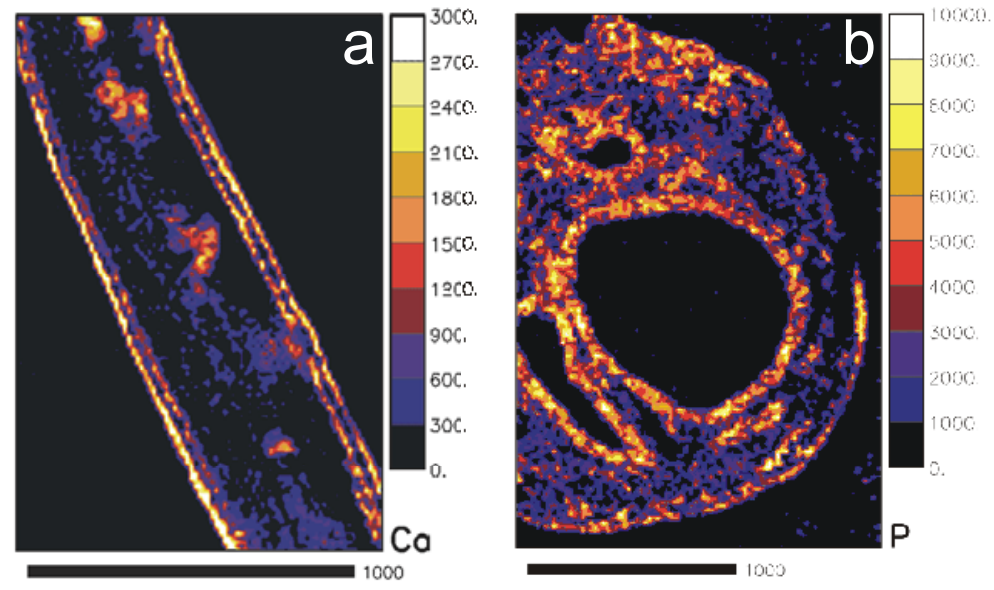